\title{
Synthesis and Study on Structural, Morphological and Magnetic properties of nanocrystalline Manganese Oxide
}

\author{
T. Shrividhya \\ Alagappa University, \\ Karaikudi, India
}

\author{
G.Ravi \\ Alagappa University, \\ Karaikudi, India
}

\author{
T.Mahalingam \\ Karunya University, \\ Coimbatore, India
}

\author{
Y.Hayakawa \\ Shizuoka University, \\ Hamamatsu, Japan
}

\begin{abstract}
Mn}_{3} \mathrm{O}_{4}$ nanoparticles were prepared by co-precipitation method followed by annealing of samples at $300{ }^{\circ} \mathrm{C}$ for 2 hours. The samples were characterized to find the structural, functional, optical, morphological, compositional and magnetic properties by PXRD, FTIR, Micro-Raman, HRSEM, TEM, XPS, EDX and VSM respectively. Structural studies by PXRD indicate that the annealing has strongly influenced the phase transition showing two coexisting phases of $\mathrm{Mn}_{2} \mathrm{O}_{3}$ and $\mathrm{Mn}_{3} \mathrm{O}_{4}$. Micro-Raman spectra showed the presence of $\mathrm{A}_{1 \mathrm{~g}}$ mode of vibration corresponding to $\mathrm{Mn}_{3} \mathrm{O}_{4}$ phase. Magnetic studies of the as synthesized $\mathrm{Mn}_{3} \mathrm{O}_{4}$ nanoparticles depict paramagnetic behavior at room temperature.
\end{abstract}

Keywords: manganese oxide, co precipitation, magnetic properties

\section{INTRODUCTION}

In recent past, considerable research attention is paid on $\mathrm{Mn}$ based compounds as it has many interesting properties that can be tailored for numerous applications. $\mathrm{Mn}_{3} \mathrm{O}_{4}$ is an important transition metal oxide due to its extensive applications in magnetic [1], electrochemical [2], $\mathrm{Li}$ ion batteries [3], catalytic applications [4], supercapacitors [5] and dilute magnetic semiconductor [6]. $\mathrm{Mn}_{3} \mathrm{O}_{4}$ nanoparticles have been synthesized in several methods like hydrothermal [7], combustion method [8], microwave assisted solution method [9], and co precipitation method [10]. In this report, we have attempted to optimize $\mathrm{Mn}_{3} \mathrm{O}_{4}$ nanoparticles by facile coprecipitation method as it is simple and cost effective technique. As synthesized nanoparticles were annealed to 300 ${ }^{\circ} \mathrm{C}$ and their structural, morphological, functional, compositional and magnetic properties were compared.

\section{EXPERIMENTAL PROCEDURE}

\subsection{Synthesis of Manganese Oxide Nanoparticles}

All chemicals used were of AR grade and was used without further purification. A simple chemical co precipitation method was employed to synthesis $\mathrm{Mn}_{3} \mathrm{O}_{4}$ nanoparticles. $1 \mathrm{M}$ of $\mathrm{MnSO}_{4} \cdot \mathrm{H}_{2} \mathrm{O}$ was dissolved in de-ionized water. $2 \mathrm{M}$ of $\mathrm{NaOH}$ was added drop wise to this solution and $\mathrm{pH}$ was maintained at $11 \pm 0.2$ by adding ammonia. Solution was stirred continuously under constant temperature $\left(60{ }^{\circ} \mathrm{C}\right)$ for 2 hours for precipitation of nanoparticles. Then precipitated particles was collected and washed with de-ionized water 2 to 3 times and dried in hot air oven at $100{ }^{\circ} \mathrm{C}$ for 12 hours. As synthesized particles was annealed at $300^{\circ} \mathrm{C}$ for 2 hours.

\section{RESULTS AND DISCUSSION}

\subsection{Structural Studies}

Figure 1 show the powder $\mathrm{X}$-ray diffractograms of as synthesized and annealed nanoparticles, which reveals the presence of mixed phases of $\mathrm{Mn}_{3} \mathrm{O}_{4}$ and $\mathrm{Mn}_{2} \mathrm{O}_{3}$. PXRD pattern of as synthesized nanoparticles show predominant peak with reflection (311) at $34.06^{\circ}$ which indicates the presence of $\mathrm{Mn}_{3} \mathrm{O}_{4}$ phase with cubic structure, whereas annealed sample shows predominant peak with reflection (222) at $32.45^{\circ}$ which can be assigned to $\mathrm{Mn}_{2} \mathrm{O}_{3}$ phase with cubic structure. The reflections (222) at $36.06^{\circ}$ and (440) at $60.24^{\circ}$ can be assigned to $\mathrm{Mn}_{3} \mathrm{O}_{4}$ phase. These values are in good agreement with JCPDS card \# 040-732. The peaks with reflection $(200)$ at $19^{\circ},(220)$ at $29^{\circ},(222)$ at $32.45^{\circ},(400)$ at $37.9^{\circ},(332)$ at $44.52^{\circ}$ and (600) at $58.29^{\circ}$ belongs to $\mathrm{Mn}_{2} \mathrm{O}_{3}$ phase with cubic structure. These peaks are well matched with JCPDS card \# 89-4836. Aroused peak intensity of annealed nanoparticles is due to the increase in crystallinity. Due to annealing, there is shift in peak to (222) which is the crystallographic plane indicating the phase change to $\mathrm{Mn}_{2} \mathrm{O}_{3}$ and this may be due to oxidation of $\mathrm{Mn}_{3} \mathrm{O}_{4}$ to $\mathrm{Mn}_{2} \mathrm{O}_{3}$ begins at as low as temperature at $300^{\circ} \mathrm{C}$ [11-12].

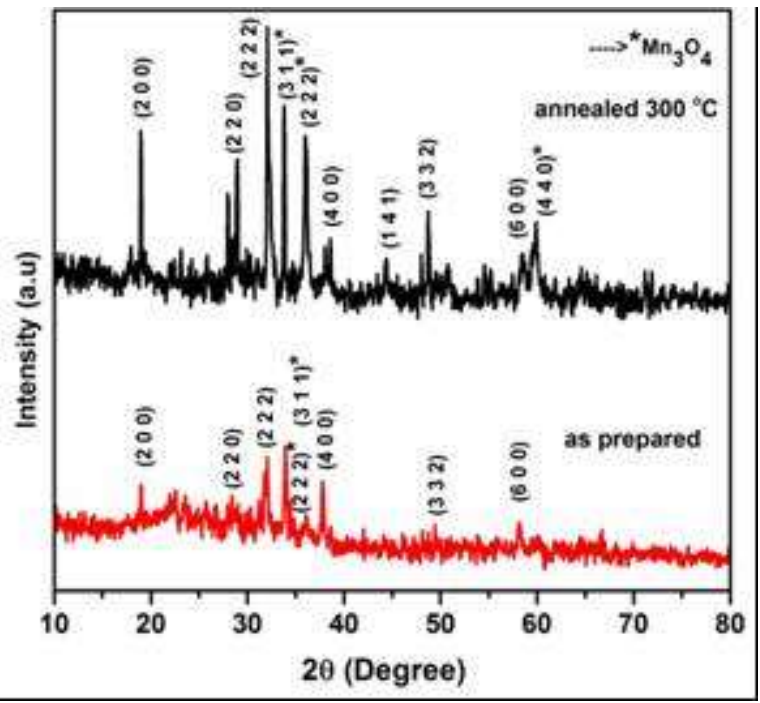

Figure 1. PXRD diffractograms of as synthesized and annealed mixed phases of $\mathrm{Mn}_{3} \mathrm{O}_{4}$ nanoparticles.

The microstructural parameters like crystallite size, microstrain, dislocation density and lattice strain [13] were calculated and tabulated in tables $1 \& 2$. It is observed that the crystallite size increased for annealed nanoparticles, while the micro strain and dislocation density were decreased. This depicts increase in crystallinity of nanoparticles. Annealing has showed a significant effect in the structural properties of manganese oxide.

\subsection{Compositional Studies}

Figure 2 shows XPS survey spectrum scanned in the binding energy range between 0 to $1100 \mathrm{eV}$ for as synthesized $\mathrm{Mn}_{3} \mathrm{O}_{4}$ nanoparticles to collect chemical composition and electronic 
states data at surface of the samples. Inset picture shows narrow window scan of $\mathrm{Mn} 2 \mathrm{p}$ state. The survey spectrum shows the presence of $\mathrm{Mn}, \mathrm{C}$ and $\mathrm{O}$ with the presence of no other impurities. The $\mathrm{C} 1 \mathrm{~s}(284.5 \mathrm{eV})$ peak was used for the calibration of the spectrum as internal reference. Electronic states of Mn 3s, O 1s, Mn 2p and Mn 3p are well matched with earlier reported values [2]. The peak at $642.7 \mathrm{eV}$ can be assigned to $\mathrm{Mn} 2 \mathrm{p}_{3 / 2}$ corresponding to $\mathrm{Mn}^{3+}$ and $48 \mathrm{eV}$ can be assigned to $3 \mathrm{p}_{3 / 2}$ electronic state [14]. Spin orbit splitting between $\mathrm{Mn} 3 \mathrm{p}_{1 / 2}$ and $\mathrm{Mn} 2 \mathrm{p}_{3 / 2}$ is $11.8 \mathrm{eV}$ which is nearer to literature reports [7].The binding energies at the $\mathrm{Mn} 2 \mathrm{p}_{3 / 2}$ and Mn 2 $p_{1 / 2}$ peaks agree well with that of reported for $\mathrm{Mn}_{3} \mathrm{O}_{4}$ indicating oxidation state for Mn [5].

Figure $3(\mathrm{a} \& \mathrm{~b})$ shows EDX spectra of as synthesized and annealed nanoparticles. It indicates the presence of $\mathrm{Mn}$ and $\mathrm{O}$ with the presence of no other impurities.

Table 1. Lattice parameters of as synthesized and annealed $\mathrm{Mn}_{3} \mathrm{O}_{4}$ nanoparticles

\begin{tabular}{|c|c|c|c|}
\hline Sample & $\begin{array}{c}\text { Lattice } \\
\text { Parameter }(\mathbf{\AA})\end{array}$ & $\begin{array}{c}\text { Volume } \\
\left(\AA^{\mathbf{3}}\right)\end{array}$ & $\begin{array}{c}\text { lattice } \\
\text { distortio } \\
\mathbf{n}(\mathbf{\AA}) \\
\mathbf{V}-\mathbf{V}_{\mathbf{0}}\end{array}$ \\
\hline $\begin{array}{c}\text { As- } \\
\text { synthesized }\end{array}$ & 8.7566 & 671.428 & 12.92 \\
\hline Annealed & 8.7887 & 678.850 & 20.35 \\
\hline
\end{tabular}

Table 2. Microstructural parameters of as synthesized and annealed $\mathrm{Mn}_{3} \mathrm{O}_{4}$ nanoparticles

\begin{tabular}{|c|c|c|c|}
\hline Samples & $\begin{array}{c}\text { Crystallite } \\
\text { size (nm) } \\
D=0.9 \lambda / \beta \operatorname{Cos} \theta\end{array}$ & $\begin{array}{c}\begin{array}{c}\text { Dislocation } \\
\text { density }\left(10^{15}\right. \\
\left.\text { lines } / \mathbf{m}^{2}\right)\end{array} \\
\delta=1 / \mathbf{D}^{2}\end{array}$ & $\begin{array}{c}\text { Micro } \\
\text { strain } \\
\left(\operatorname{lines}^{-2} \mathrm{~m}^{-4}\right) \\
\varepsilon=\beta \operatorname{Cos} \theta / 4\end{array}$ \\
\hline $\begin{array}{c}\text { As } \\
\text { synthesized }\end{array}$ & 31.7 & 0.996 & 0.0011 \\
\hline Annealed & 91.6 & 0.119 & 0.0004 \\
\hline
\end{tabular}

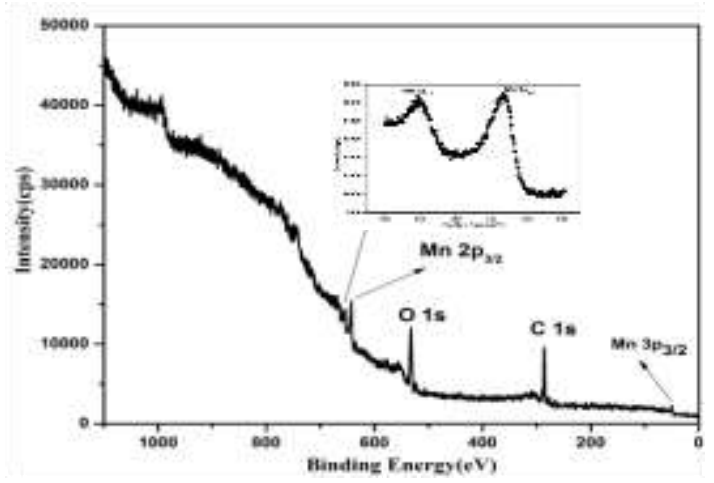

Figure. 2 XPS spectrum of as synthesized $\mathrm{Mn}_{3} \mathrm{O}_{4}$ nanoparticles. Inset

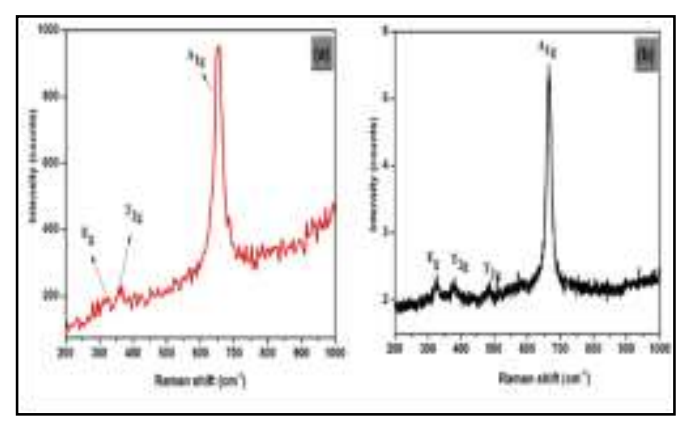

Figure. 3 EDS spectra of (a) as synthesized and (b) annealed $\mathrm{Mn}_{3} \mathrm{O}_{4}$ nanoparticles

\subsection{Functional Studies}

The Raman scattering measurements were performed using the $514.5 \mathrm{~nm}$ excitation line from $\mathrm{Ar}^{+}$laser. Figure $4(\mathrm{a} \& \mathrm{~b})$ shows the micro-Raman spectra of as synthesized and annealed nanoparticles respectively. As synthesized nanoparticles exhibits three phonon peaks at (doubly degenerate) $T_{2 \mathrm{~g}}$ symmetry mode at $366 \mathrm{~cm}^{-1}, \mathrm{E}_{\mathrm{g}}$ symmetry mode at $320 \mathrm{~cm}^{-1}$ and a single degenerate $A_{1 \mathrm{~g}}$ symmetry mode at $654 \mathrm{~cm}^{-1}$. The band corresponding to $654 \mathrm{~cm}^{-1}$ is very close to $655 \mathrm{~cm}^{-1}$ which is due to the stretching vibration of $\mathrm{Mn}-\mathrm{O}$ in $\mathrm{Mn}_{3} \mathrm{O}_{4}$ [7]. Annealed nanoparticles shows four phonon peaks same as synthesized particles with one extra band $T_{2 \mathrm{~g}}$ symmetry mode at $487 \mathrm{~cm}^{-1}$ which may be due to the out of plane bending mode of $\mathrm{Mn}_{2} \mathrm{O}_{3}$ phase. Presence of mixed phase of $\mathrm{Mn}_{2} \mathrm{O}_{3}$ and $\mathrm{Mn}_{3} \mathrm{O}_{4}$ is confirmed from these peaks. Also peak intensity of annealed nanoparticles is lesser than that of as synthesized particles. This may be due to increase in crystallite size for annealed nanoparticles which can be explained using phonon confinement effect as reported earlier by Jian Zuo et al [27].
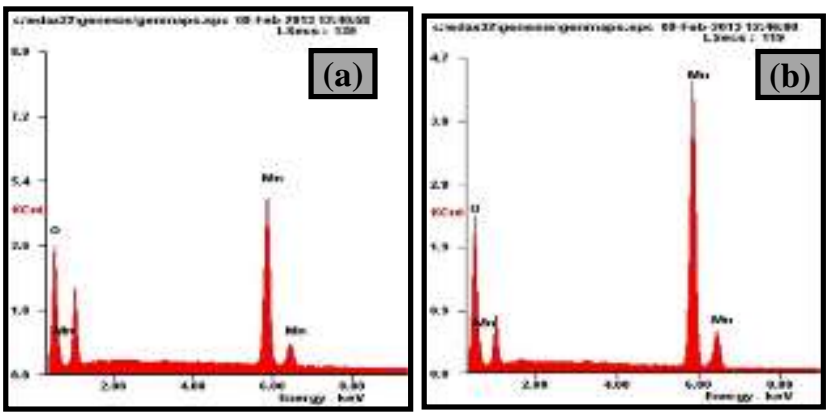

Figure. 4 Raman spectra of (a) as synthesized and (b) annealed $\mathrm{Mn}_{3} \mathrm{O}_{4}$ nanoparticles.

FTIR spectra for as synthesized and annealed nanoparticles are shown in figure $5(\mathrm{a} \& \mathrm{~b})$. In the region 400 to $700 \mathrm{~cm}^{-1}$, the bands observed at $429 \mathrm{~cm}^{-1}, 458 \mathrm{~cm}^{-1}, 513 \mathrm{~cm}^{-1}$ and $609 \mathrm{~cm}^{-1}$ corresponds to the $\mathrm{Mn}-\mathrm{O}$ vibrations ascribed to the stretching modes of octahedral and tetrahedral sites of $\mathrm{Mn}_{3} \mathrm{O}_{4}$ [16]. The bands at $1110 \mathrm{~cm}^{-1}$ and $1633 \mathrm{~cm}^{-1}$ are due to the $\mathrm{O}-\mathrm{H}$ bending vibrations along with $\mathrm{Mn}$ [17]. The broad absorption peak at $3443 \mathrm{~cm}^{-1}$ indicates the presence of hydroxide group. Annealed nanoparticles exhibits an extra peak observed at 995 $\mathrm{cm}^{-1}$ which may be attributed to $\mathrm{M}=\mathrm{O}$ vibration of $\mathrm{Mn}_{2} \mathrm{O}_{3}$. 


\subsection{Morphological Studies}

HRSEM micrographs of as synthesized and annealed nanoparticles are shown in figure 6(a-c \& d-f), which shows irregular shaped disk like morphology with average particle size of about $155 \mathrm{~nm}$. Annealed nanoparticles also exhibit similar morphology with average particle size of about 400

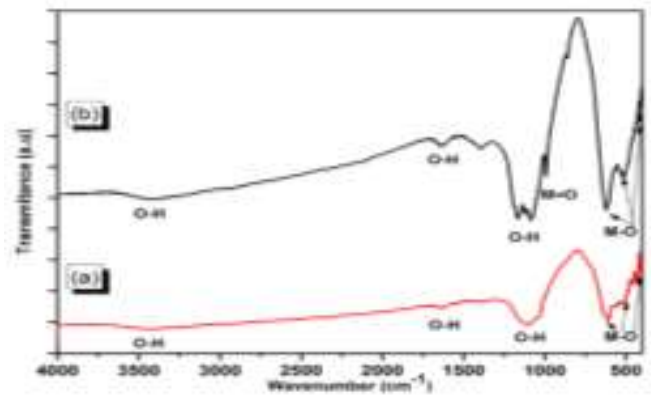

TEM micrograph (figure 7) of as synthesized nanoparticles was also taken as supporting information. It confirms similar morphology with particle size of $155 \mathrm{~nm}$.

Figure. 5 FTIR spectra of (a) as synthesized and (b) annealed $\mathrm{Mn}_{3} \mathrm{O}_{4}$ nanoparticles

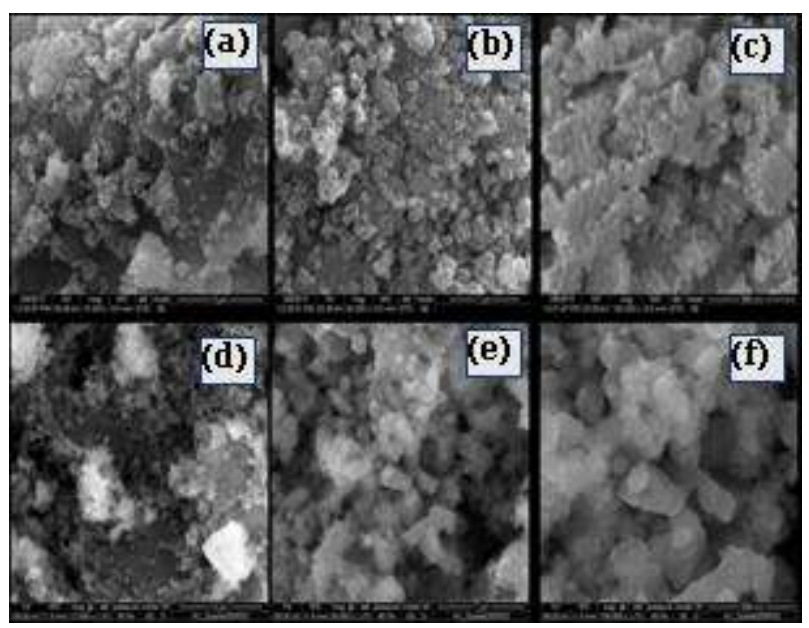

Figure 6. SEM micrographs of (a-c) as synthesized and (d-f) annealed $\mathrm{Mn}_{3} \mathrm{O}_{4}$ nanoparticles

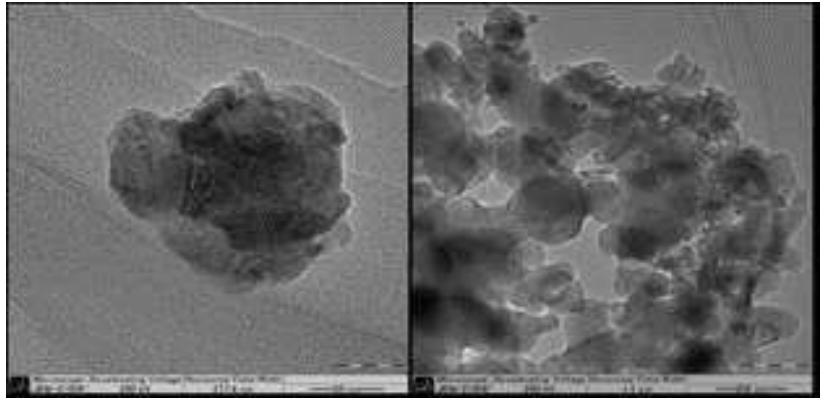

Figure 7. TEM micrographs of as synthesized $\mathrm{Mn}_{3} \mathrm{O}_{4}$ nanoparticles

\subsection{Magnetic studies}

Magnetic behaviors of as synthesized and annealed $\mathrm{Mn}_{3} \mathrm{O}_{4}$ nanoparticles are shown in figure 8 . This magnetic study was carried out in room temperature with maximum magnetic field at 15 KOe. Both as synthesized and annealed $\mathrm{Mn}_{3} \mathrm{O}_{4}$ nanoparticles exhibit paramagnetic behavior. The maximum magnetizations observed were $0.2864 \mathrm{emu} / \mathrm{g}$ and 0.5347 $\mathrm{emu} / \mathrm{g}$ for as synthesized and annealed nanoparticles at maximum field. Magnetic ordering of annealed samples is increased with increase in crystallinity of the samples. [19]

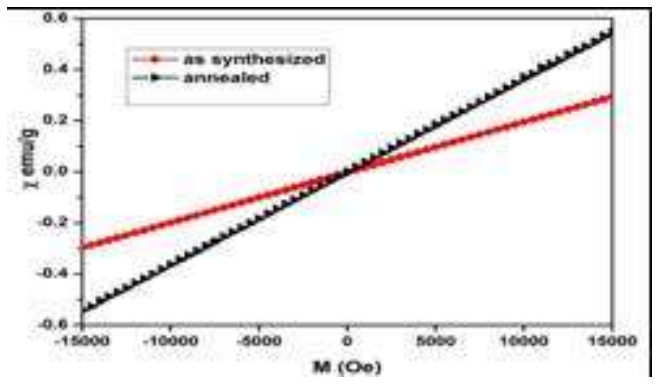

Figure 8. Room temperature magnetization curves of as synthesized and annealed $\mathrm{Mn}_{3} \mathrm{O}_{4}$ nanoparticles

\section{CONCLUSION}

$\mathrm{Mn}_{3} \mathrm{O}_{4}$ nanoparticles were synthesized by co-precipitation method and their annealing effect was reported. PXRD revealed mixed phases of $\mathrm{Mn}_{3} \mathrm{O}_{4}$ and $\mathrm{Mn}_{2} \mathrm{O}_{3}$. Annealing of nanoparticles at $300{ }^{\circ} \mathrm{C}$ has favored the growth orientation towards $\mathrm{Mn}_{2} \mathrm{O}_{3}$ phase due to oxidation of $\mathrm{Mn}_{3} \mathrm{O}_{4}$. Increased peak intensity and decreased microstrain and dislocation density indicates the increase in crystallinity for annealed samples. XPS spectra proved the presence of $\mathrm{Mn}$ and $\mathrm{O}$ with presence of no other impurities. EDS also confirmed the composition of the samples. HRSEM micrographs showed irregular shaped plates with average particle size of $155 \mathrm{~nm}$ for as synthesized particles and $400 \mathrm{~nm}$ for annealed particles. TEM micrograph further confirmed similar morphology with particle size almost same as $155 \mathrm{~nm}$. Functional studies were carried out using micro Raman and FTIR. Various bending and stretching modes of $\mathrm{Mn}-\mathrm{O}$ and $\mathrm{O}-\mathrm{H}$ groups were analyzed from these spectroscopic studies. Room temperature magnetic studies confirmed that the paramagnetic behavior of $\mathrm{Mn}_{3} \mathrm{O}_{4}$ nanoparticles improved for annealed samples due to increase in crystallinity. 


\section{REFERENCES}

[1] Lin He, 2010, Solid State Communications, 150, 743.

[2] Peng Li, Caiyun Nan, Zhe Wei, Jun Lu, Qing Peng, Yadong Li, 2010, Chemistry of materials, 22, 4232.

[3] Changbin Wang, Longwei Yin, Dong Xiang, Yongxin Qi, 2012 Applied materials and interfaces, 4, 1636.

[4] Yi-Fan Han, Kanaparthi Ramesh, Luwei Chen, Effendi Widjaja, Srilakshmi Chilukoti, Fengxi Chen, 2007, Journal of physical chemistry C, 7, 111 .

[5] Dubal, D.P., Dhawale, D.SSalunkhe, R.R Lokhande C.D., Journal of Electroanalytical Chemistry, 2010, 647, 60.

[6] Duofa Wang, Sangyoon Park, Yongsu Lee, Taiwoon Eom, Seongjae Lee, Young Pak Lee, Cheljong Choi, Jinchai Li, Chang Liu, 2009, Crystal growth and design, 5,2124 .

[7] Yong Cai Zhang, Tao Qiao, Xiao Ya Hu, 2004, Journal of Solid State Chemistry, 177, 4093.

[8] Gopalakrishnan, I.K., Bagkar. N., Ganguly, R., Kulshreshtha, S.K., 2005, Journal of Crystal Growth, 280,436 .

[9] Li-Xia Yanga, Ying-Jie Zhua, Hua Tonga, Wei-Wei Wanga, Guo-Feng Cheng, 2006, Journal of Solid State Chemistry, 179, 1225.

[10] He. X. Wang. Z.H. Geng, D.Y., Zhang, Z.D. 2011, Journal of Material Science Technology, 27, 503.

[11] Gillot, B., El Guendouzi, M., Laarj. M., 2001, Materials Chemistry and Physics, 70, 54

[12] Irene Rusakova, Teyeb Ould-Ely, Cristina Hofmann, Dario Prieto-Centurion, Carly S. Levin, Naomi J. Halas, Andreas Luttge, Kenton H. Whitmire, 2007, Chemistry of materials, 19, 1369 .

[13] Mahalingam, T., Thanikaikarasan. S., Dhanasekaran..V., Kathalingam. A., Velumani. S., Jin-Koo Rhee, 2010, Material Science of Engineering B, 174, 257.

[14] Wagner, C. D., Riggs, W. M. , Davis, L. E., Moulder. J. F., Handbook of X-ray Photoelectron Spectroscopy. First ed., Perkin-Elmer Corporation, 1979.

[15] Jian Zuo, Cunyi Xu, Yunpiug Liu, Yitai Qian, 1998, Nanostructured Materials, 10, 1331.

[16] Pierre Gibot, Lydia Laffont, 2007, Journal of Solid State Chemistry, 180, 695.

[17] Dubal. D.P., Dhawale, Gujar, T.P., Lokhande, C.D. , 2011, Applied Surface Science, 257, 3378.

[18] Brian Smith, Infrared Spectral Interpretation: A Systematic Approach, First ed., CRC press, 1999.

[19] Stephen Blundell, Magnetism in Condensed Matter, First ed., Oxford University Press Inc., New York, 2001. 